\title{
Towards a representative periphytic diatom sample
}

\author{
J. Fisher and M.J. Dunbar \\ Centre for Ecology and Hydrology, Wallingford, Crowmarsh Gifford, Wallingford, Oxon 0X10 8BB, UK. \\ Email for corresponding author: J.Fisher@Apemltd.co.uk
}

\begin{abstract}
The need to acquire a representative periphytic diatom sample for river water quality monitoring has been recognised in the development of existing diatom indices, important in the development and employment of diatom monitoring tools for the Water Framework Directive. In this study, a nested design with replication is employed to investigate the magnitude of variation in diatom biomass, composition and Trophic Diatom Index at varying scales within a small chalk river. The study shows that the use of artificial substrates may not result in diatom communities that are typical of the surrounding natural substrates. Periphytic diatom biomass and composition varies between artificial and natural substrates, riffles and glides and between two stretches of the river channel. The study also highlights the existence of high variation in diatom frustule frequency and biovolume at the individual replicate scale which may have implications for the use of diatoms in routine monitoring.
\end{abstract}

Keywords: periphyton, diatom, river, Pang, monitoring, diatom indices, Trophic Diatom Index

\section{Introduction}

The Water Framework Directive (WFD) emphasises the concept of ecological status (OJEC, 2000; Logan and Furse, 2002) and requires member states to develop standards for its assessment. It aims to present a holistic view of status through assessment of several of the ecological groups in a water body. In rivers, the periphytic flora is one such indicator. In this paper an assessment is made of some of the environmental constraints affecting the ability to obtain representative periphytic samples for a biological system which is seen as complex and highly heterogeneous. Using field data, variation in diatom flora is examined at differing spatial resolutions to gain an understanding of the variation inherent in the channel environment resulting from agricultural disturbance, stream morphology and substrate.

Diatoms, a predominant component of the periphyton, have long been used as a tool for monitoring surface water quality. For example, the Trophic Diatom Index (TDI) has been designed to monitor the effect of sewage discharge for the Urban Wastewater Directive, for routine water quality monitoring in Europe (Kelly and Whitton, 1995; Whitton and Rott, 1996) and for the study of abstraction and 'ecologically acceptable' flows (Smolar et al., 1998; Growns and Growns, 2001). Diatom-based indices are also currently being developed to determine the ecological status of rivers for the Water Framework Directive. European projects such as STAR (EVK1-CT 2001-00089), completed in 2005, and AQEM (EVK1-CT 1999-00027), completed in 2002, have moved towards a harmonisation of biological indices and monitoring techniques across Europe. Further, factors influencing the diatom composition and diatom indices, other than water quality, need to be further understood if such widely applicable monitoring tools are to be developed.

There is a growing body of evidence suggesting that river periphytic diatom composition and biomass can differ between substrates (Hill et al., 2000; Potapova, 1996; Potapova and Charles, 2005). However, few studies have examined variation occurring between replicate samples or between different physical habitats. When sampling periphyton there is a host of decisions concerning which substrate to sample from and from which exact point in rivers and streams. Kelly et al. (1998) note that for the purpose of sampling for the TDI, rocks and hard surfaces are preferred and that the validity of comparison of indices between epilithic and epiphytic samples is uncertain. It is also advised that, if artificial substrates have to be used, they are left in 
situ for at least four weeks (Kelly et al., 1998, 2001). This paper examines the variation in periphytic diatom biomass, composition and in the TDI resulting from the sampling of artificial and natural substrates, from different physical habitats (riffles and glides) and between two adjacent stretches of river.

\section{Sample site}

The River Pang drains an area of $171 \mathrm{~km}^{2}$ which is predominately pastural agriculture overlying Cretaceous Chalk (Neal et al., 2004a,b). At the Pang study area, near Hampstead Norreys, Berkshire, the river has a wetted width of approximately seven metres and, during the study period, depths of $12-45 \mathrm{~cm}$. The predominate form of nitrogen, nitrate-nitrogen, has an annual mean concentration of $7.38 \mathrm{mg} \mathrm{l}^{-1}$ and the predominant form of phosphorus is SRP, with an annual mean concentration of $69 \mu \mathrm{g} \mathrm{l}^{-1}$ (Neal et al., 2004a,b). If any algal nutrient limitation exists, phosphorus is likely to be the limiting nutrient under such circumstances (Redfield, 1958). The in-stream vegetation is predominantly of Ranunculus spp. and the river bed substrate consists of stones and gravel. Sampling was conducted at two sites, $800 \mathrm{~m}$ apart. Along the upstream section a fence had been erected in 2003 along $200 \mathrm{~m}$ of both banks of the river to prevent cattle access and 800 metres downstream an unfenced area was studied. Both sections are situated within a single farm and run through adjoining fields of pasture. As well as glass slide substrates, the periphyton on Ranunculus and stones was sampled, in riffle (defined as shallower areas with significant areas of rippled and standing wave surface flow types (Harper et al., 2000)) and glides (deeper non-riffle habitats with mainly smooth surface flow).

The influence of two factors on the periphytic diatom composition was studied:

(1) Substrate: Comparison of periphyton species composition and TDI on glass slides, stones and submerged macrophytes,

(2) Physical habitat: Investigation into the variations in periphyton biomass, composition and TDI on all three substrates in glides and riffles and between the two stretches of river.

\section{Methods}

MACROPHYTE AND STONE SUBSTRATE

Twelve epilithic samples, each consisting of three stones, were removed from the stream bed. Six samples were removed from the fenced and six from the unfenced stretch, and within each stretch three of these were from riffle areas and three from glide areas. Pebbles were not taken where there might be shading from vegetation. Submerged Ranunculus spp. samples were taken in the same manner from fenced and unfenced areas, from glides and riffles. Care was taken to ensure that whole Ranunculus spp. stalks were taken, comprising of stalk and leaf. No Ranunculus spp. samples were taken from glide areas within the fenced stretch as there were no Ranunculus plants present.

\section{GLASS SLIDE SUBSTRATE}

Glass slides were attached to bricks, three slides per brick, and six bricks placed within the stream in both the fenced area and the unfenced area. Three were placed in shallower riffles and three in the deeper glide areas. The bricks placed in the riffle areas were in shallower water $(t$-test, $\mathrm{p}<0.01)$ in an average water depth of $9 \mathrm{~cm}$, than in glide areas where average water depth was $21 \mathrm{~cm}$. All bricks were placed away from in-stream and marginal vegetation to prevent shading. The bricks were placed in the stream in June 2004 and removed exactly one month later.

The glass slides, stones and Ranunculus samples were carefully returned to the laboratory and the periphyton removed and preserved that day. Periphyton was removed from all substrates by brushing with a toothbrush, which was then washed into a known volume of distilled water and preserved in lugols.

\section{PERIPHYTON SLIDE PREPARATION}

$0.5 \mathrm{ml}$ of each preserved algae sample was heated on a glass cover slip until the droplet had dried and then mounted in Naphrax. At least 200 diatom frustules per slide were examined under oil immersion at a thousand times magnification and diatom frustules identified to species, where possible, using the taxonomy of Krammer and LangeBertalot (1999). The length, widths or diameters of at least ten frustules of each species were measured and converted to biovolumes using standard formulae for geometric shapes. The presence of other non-diatom taxa was noted using an inverted microscope at four hundred times magnification.

\section{DATA ANALYSIS}

Trophic diatom index was calculated following the method described in Kelly and Whitton (1995) and Kelly et al. (2001). This, initially, involved the calculation of the weighted mean sensitivity (WMS) to nutrient pollution using the equation of Zelinka and Marvan (1961) (Eqn. 1) and then converted to TDI (Eqn. 2). 


$$
\mathrm{WMS}=\frac{\sum\left(a^{*} s^{*} v\right)}{\sum\left(a^{*} v\right)}
$$

where $a=$ abundance of each species, $s=$ sensitivity to nutrients (1-5) and $v=$ value as an indicator (1-3) (see Kelly et al., 2001).

$$
\mathrm{TDI}=(\mathrm{WMS} * 25)-25
$$

The data on frustule frequency, biovolume, TDI, species richness and \% motile frustules from the slides were analysed using a mixed effects model (Pinhero and Bates, 2000) with the fenced/unfenced and habitat type as crossed fixed effects, with brick as a random effect and slides considered as replicates within bricks. This modelling strategy retains the correct degrees of freedom for testing the fixed effects, but also allows comparison of variance between bricks and slides within bricks. Random effects were estimated using residual maximum likelihood (REML), although for likelihood ratio tests comparing the fixed effects, maximum likelihood (ML) estimation was used. Data from the stones and plants and slides were analysed using analysis of variance (ANOVA), with fenced/unfenced and habitat types as factors.

Species composition in the fenced and unfenced, glide and riffles, and in the different substrates was analysed using Principle Components Analysis (PCA). PCA, a linear ordination method, was chosen after examining the species response curves for linear or unimodal responses (Jongman et al., 1995).

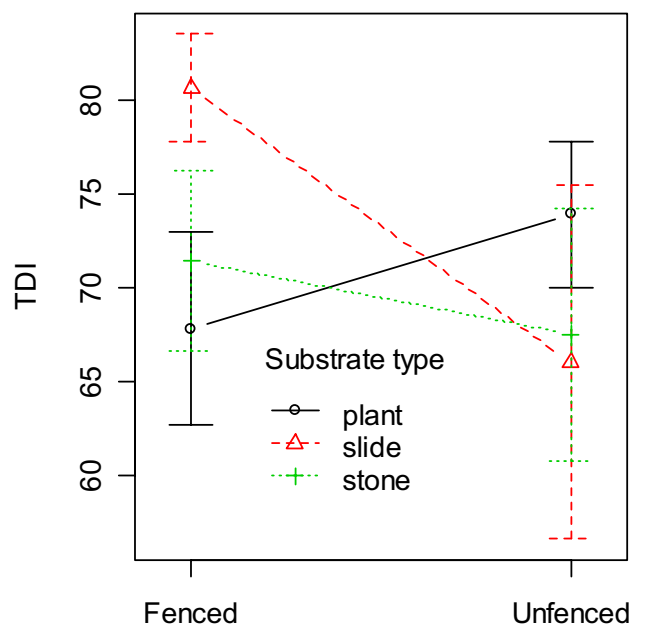

a) Fenced or Unfenced

\section{Results}

Sixty-seven diatom taxa were identified with Achnanthes delicatula, Achnanthes lanceolata, Amphora spp., Cocconeis placentula, Fragilaria pinnata, Gomphonema parvulum, Meridion circulare, and various unidentified Navicula and Nitzschia species being the most commonly occurring. The non-diatom flora were predominately the filamentous Cyanobacteria, Phormidium spp. and Oscillatoria spp.

\section{SUBSTRATE}

The TDI values calculated from the glass slides from the fenced stretch were higher than the TDI values calculated from the stones and plants when taken from the fenced area (Fig. 1a). This is manifested in a significant $\left(\mathrm{F}_{2,35}=0.0019\right.$, $\mathrm{p}<0.01)$ interaction between fenced/unfenced and substrate. All other effects were non-significant, including the three way interaction. TDI values from the three substrates did not differ significantly between riffles and glides (Fig. 1b). What stands out in Fig. 1 is the variation in TDI between replicate samples, and the variability in this variation between habitat types and fenced/unfenced sites.

Figure 2 shows the percentage of motile diatom frustules found on the substrates in the two stretches of river and in glides and riffles. While the proportion of motile diatoms was greater on the glass slides in the fenced area and on riffles than on the natural substrates, there was high variability between the replicates. However, there were no plants in any glides at the fenced site so the results should

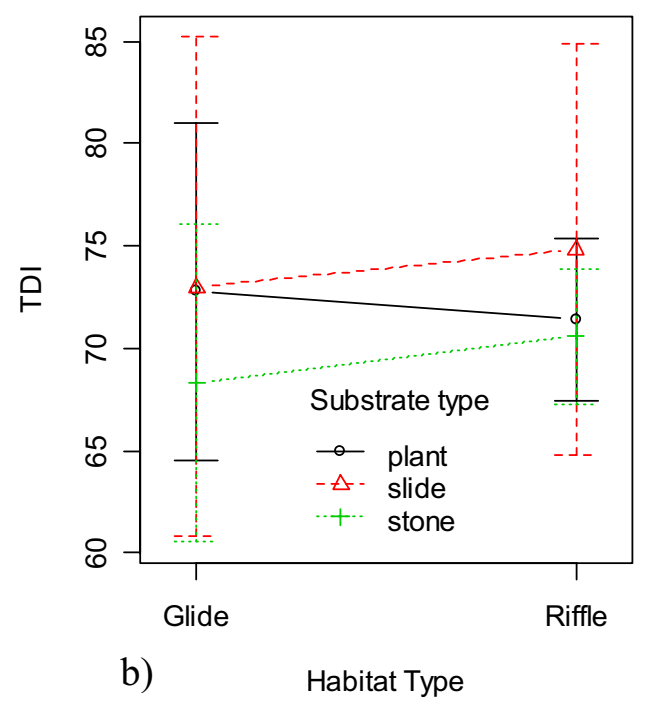

Fig. 1. Interaction plots to illustrate the differences in TDI on slides, stones and plants (a) between two stretches of the river and (b) between riffles and glides. 


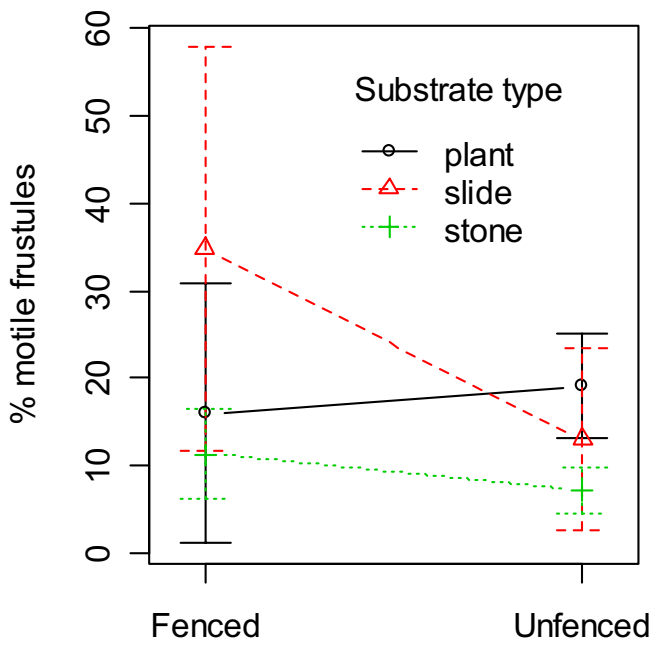

a) Fenced or Unfenced

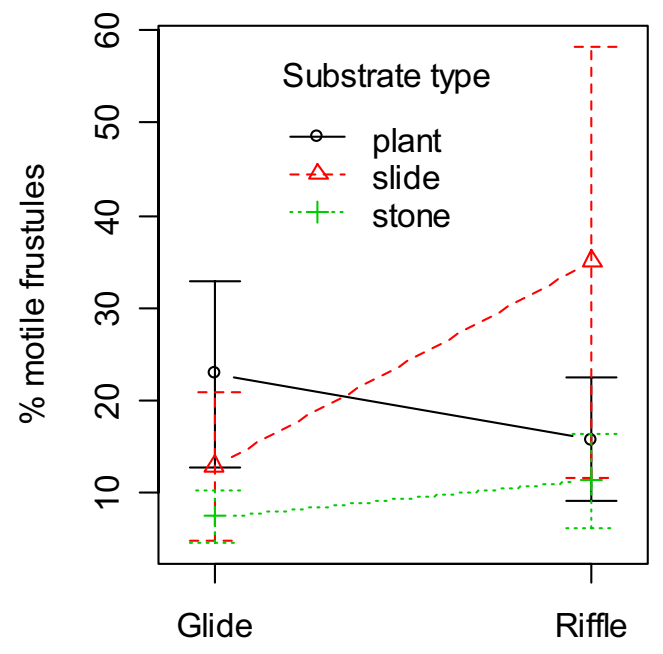

b) Habitat Type

Fig. 2. Interaction plots to illustrate the differences in percentage motile diatom frustules on slides, stones and plants (a) between two stretches of the river and (b) between riffles and glides.

be treated with caution: a re-assessment of the data for just the riffles produces similar/consistent features.

Figure 3 shows the species of diatom frustules, as a percentage of the total, found on the differing substrates in the fenced and unfenced, glide and riffle areas. The most important ordination axis $\left(\lambda_{1}=0.587\right)$ is correlated to the proportion of a variety of Nitzschia species, Aulacoseira

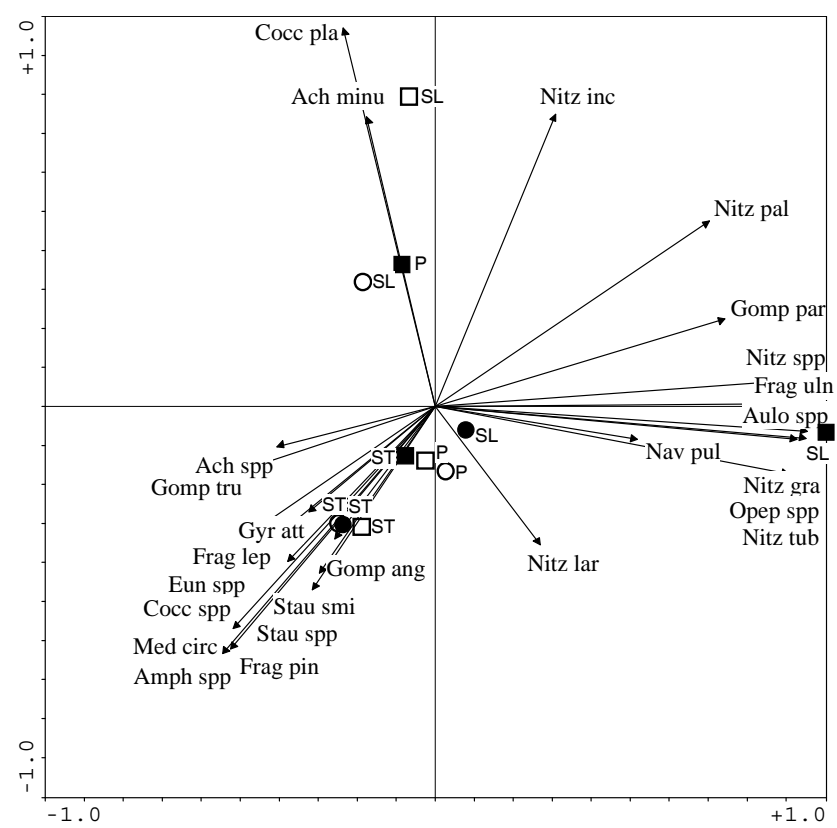

Fig. 3. PCA of frustule biovolume of the diatom taxa, expressed as a $\%$ of the total, on glass slides (SL), plants (P) and stones (ST).

$\square=$ riffle, $\quad \bigcirc=$ glide,$\quad$ shaded $=$ fenced, $\quad$ open $=$ unfenced spp. and Fragilaria ulna while the second $\left(\lambda_{2}=0.326\right)$ is correlated to Cocconeis placentula and Achnanthes minutissima. The major separation of the samples is by substrate with the above species occurring in the greatest proportion on the glass slides while, on the Ranunculus spp. and stones, the diatom species were characterised by a mix of diatom taxa, including Meridion circulare, Fragilaria spp. and Stauroneis spp. There is no clear difference in diatom species between stone or plant samples or between the fenced or unfenced glide or riffles on these natural substrates.

\section{REPLICATE SAMPLING OF SLIDES ON BRICKS}

The periphytic biomass, species composition and TDI data from the glass slides was investigated in greater detail as the nested design allowed statistical analysis of within brick, between brick and between habitat variation. The frequency of frustules $\left(\mathrm{F}_{1,8}=25.7, \mathrm{p}<0.001\right)$ and total biovolume of frustules $(\mathrm{p}<0.001)$ was significantly greater on slides placed in the fenced area than in the unfenced area (Fig. 4a,b). Frustule frequency and biovolume also tended to be higher in the riffles than glides (Wald test, $\mathrm{F}_{1,8}=6.53, \mathrm{p}=0.034$, also likelihood ratio test using $\mathrm{ML}$, ratio $=6.30, \mathrm{p}=0.012$ ). Virtually all $(>99.8 \%)$ of the residual variance was at the scale of slides within bricks, rather than between bricks.

There were significantly lower values of TDI $\left(\mathrm{F}_{1,8}=18.1\right.$, $\mathrm{p}=0.0028)$ in the unfenced section but no significant difference between riffles and glides $\left(\mathrm{F}_{1,8}=0.823, \mathrm{p}=0.39\right)$ (Fig. 4c). Once the fixed effect is fitted, the remaining variance in TDI, the residual error, is partitioned between 


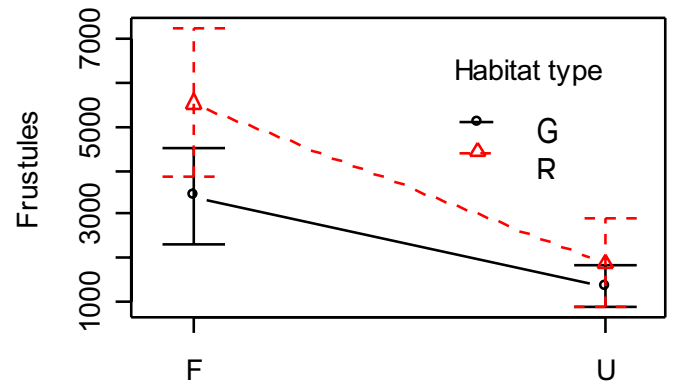

a)

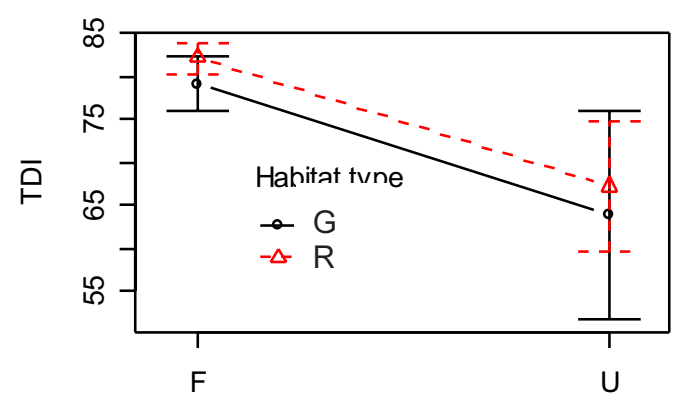

c)

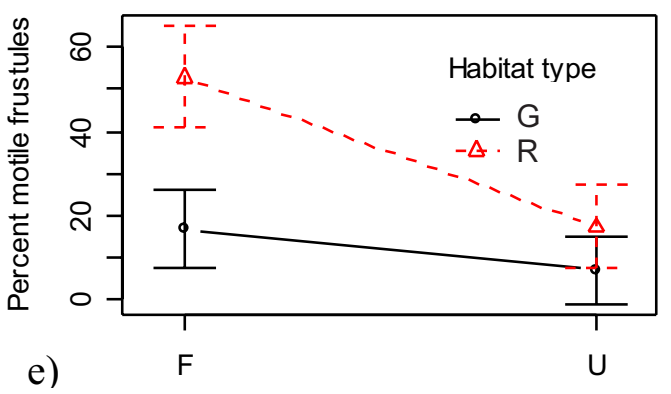

the brick (19.8), and slides between bricks (38.8). The unfenced stretch had significantly lower species richness $\left(\mathrm{F}_{1,8}=23.1, \mathrm{p}=0.0013\right)$ but there was no significant difference between glides and riffles $\left(\mathrm{F}_{1,8}=2.09, \mathrm{p}=0.19\right.$, also likelihood ratio test using $\mathrm{ML}$, ratio $=2.22, \mathrm{p}=0.14$ ) (Fig. 4d). Again, once the fixed effect is fitted, the remaining variance is almost all at the slide rather than the brick level. For percentage motile frustules, a square root transformation was first applied. There is some evidence for an interaction between the effect of stream stretch and location within stream, with there being a greater difference between the riffles and glides at the unfenced stretch (interaction term tested using likelihood ratio test and ML estimation, ratio $=3.37, \mathrm{p}=0.066$ ). Overall, glides have lower percentage motile frustules than riffles $\left(\mathrm{F}_{1,8}=14.8, \mathrm{p}=0.0049\right)$, and

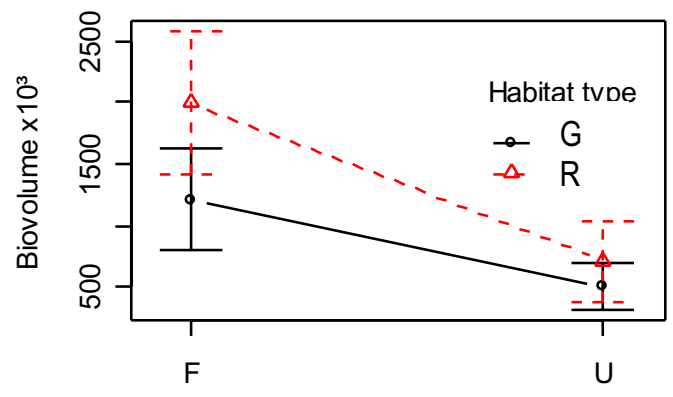

b)

Fenced or Unfenced

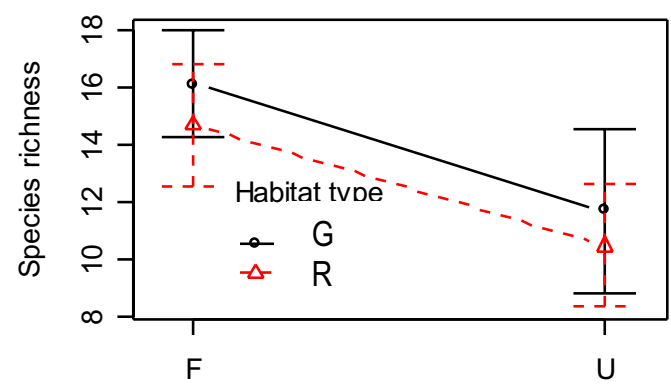

d) Fenced or Unfenced

Fig. 4. Interaction plots to illustrate the differences in mean diatom biomass and diatom indices on the glass-slides in the fenced and unfenced area, glides and riffles. a) frustule frequency, b) frustule biovolume, c) species richness, d) TDI and e) \% motility.

unfenced lower than fenced $\left(\mathrm{F}_{1,8}=18.1, \mathrm{p}=0.0028\right)$ (Fig. 1e). Once the fixed effect is fitted, $12 \%$ of the remaining variance is at the brick level, the remainder at the slide level.

Figure 5 shows the relationship between each of the single parameters calculated from the diatoms growing on the glass slides. The percentage of motile diatoms is positively correlated to frustule frequency and biovolume per slide. TDI and species richness increase with frustule frequency and biovolume initially and then fail to increase with a further increase in these measures of diatom standing-stock. Correspondingly, TDI, species richness and the percentage of motile diatoms are all weakly positively correlated.

PCA on the frequency of diatom frustules per taxa on the glass slides results in separation between the fenced and unfenced samples (Fig. 6). The first ordination axis $\left(\lambda_{1}=\right.$ 


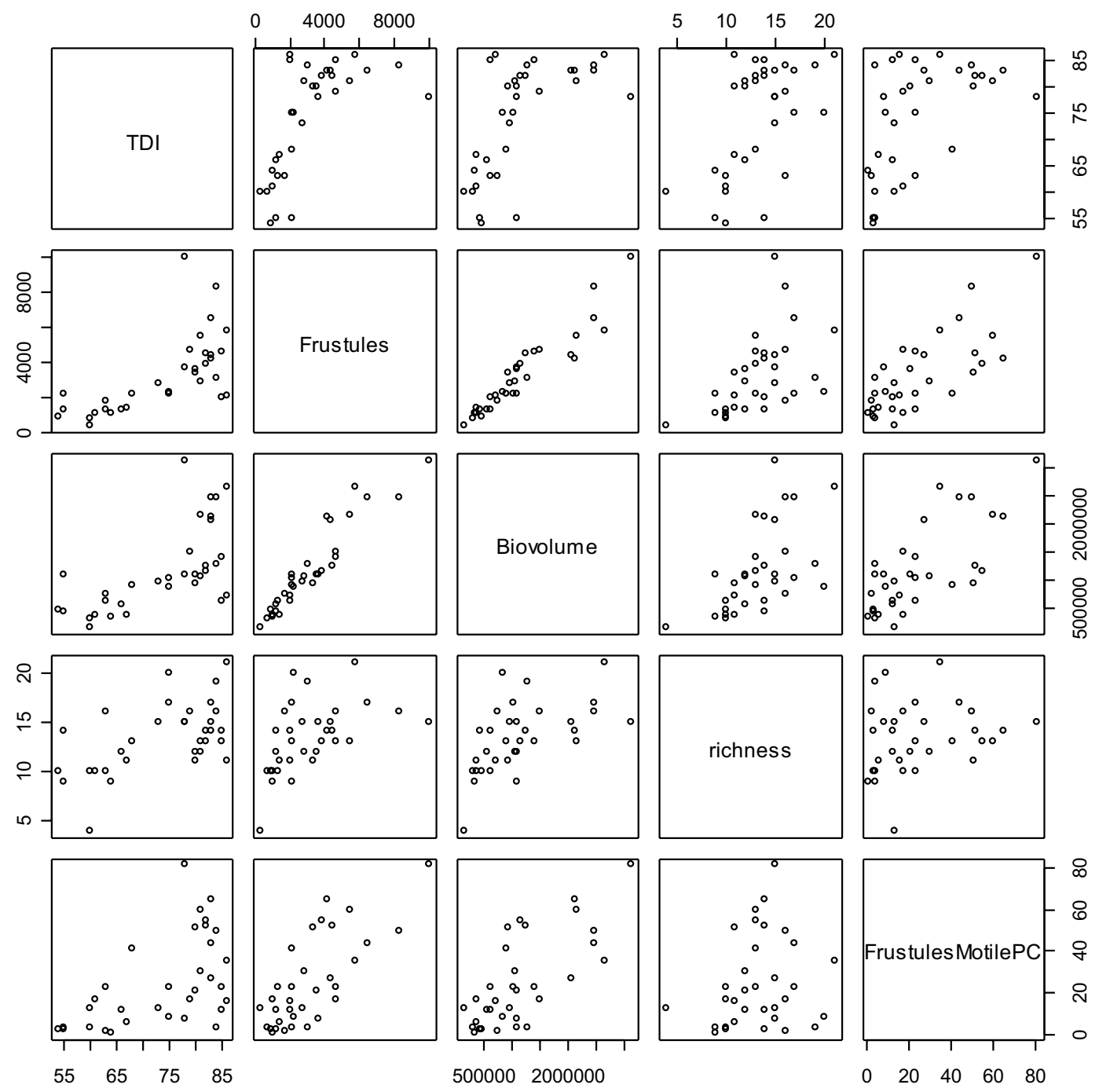

Fig. 5. Relationship between frustule frequency and biovolume and the indices for the diatoms on the glass-slides. Frustule unit $=$ number of frustules $\mathrm{mm}^{-1} \mathrm{~m}^{3}$, motile frustules $=\%$.

0.950) is correlated to the frequency of Nitzschia species while the second ordination axis explains only a small proportion of the variation $\left(\lambda_{2}=0.023\right)$ and is correlated to the frequency of a mix of diatom species. The frequency of most of the diatom species is greater on the glass slides on bricks in the fenced areas, while only the frustules of Cocconeis placentula were greater on the slides in the unfenced areas. There is also some separation of species associated with fenced riffle areas from those species associated with the fenced glide areas. Riffle areas are associated more with Nitzschia spp while the glide areas more with a mix of diatom species. There is no clear separation in species taken from the different habitat types within the unfenced stretch.

\section{Discussion}

\section{SUBSTRATE}

Despite leaving the artificial substrates in the channel for more than the minimum time recommended for analysis of the TDI (Kelly et al., 2001), the TDI values calculated for the slides at the fenced site were higher but less variable than those calculated for the two natural substrates in the fenced river stretch (Fig. 1a,b). Biggs et al. (1998) have identified some diatom species that are ruderals, which they describe as early colonisers. These include Gomphonema parvulum, Fragilaria ulna, Achnanthidium minutissimum and Cocconeis placentula. These species predominated on the glass slides but not on the stones and plants (Fig. 3). Thus, despite being in situ for a month, the diatom composition was still in the early colonisation phase. 


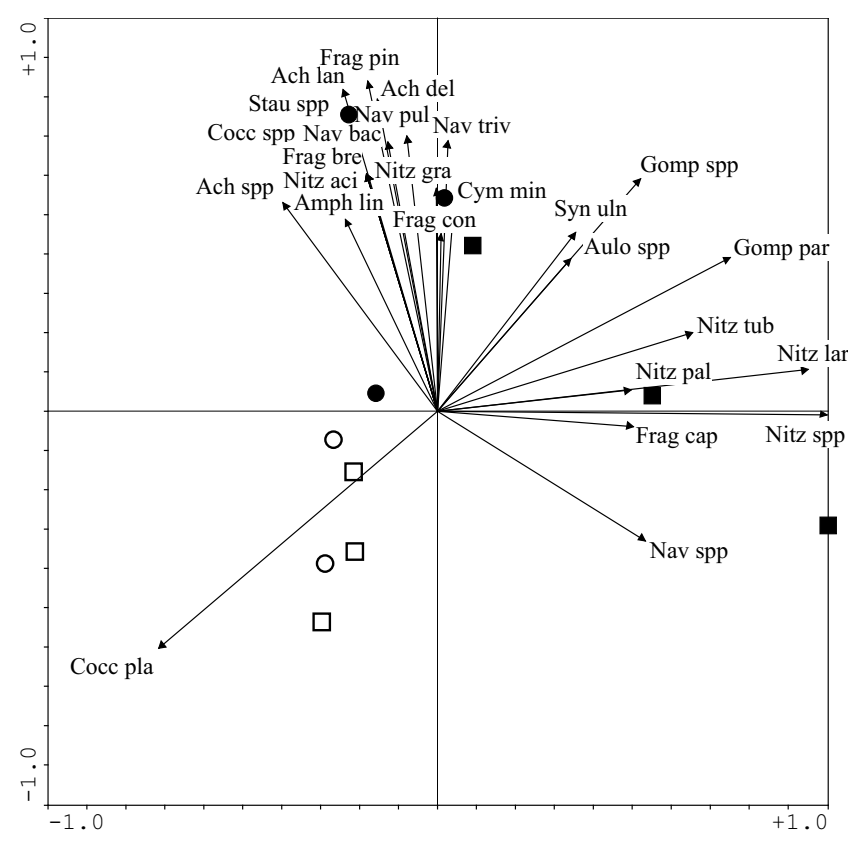

Fig. 6. PCA of frustule frequency of the diatom taxa on the glassslides. $\square=$ riffle, $\mathrm{O}=$ glide, shaded=fenced, open=unfenced .

Barbiero (2000) also concluded that glass slides diatom communities were not representative of the natural communities, while Komarek and Sukacova (2004) have shown that other introduced artificial substrates are also often characterised by periphyton indicative of more successional processes than water quality. This feature indicates that one month was insufficient to develop a representative diatom flora and the natural substrates are likely to have resulted in a more representative diatom sample. Komarek and Sukacova (2004) suggest leaving artificial substrates for a year before sampling to allow the periphyton to progress from a colonisation community to a stable community reflecting environmental conditions.

Kelly et al. (1998) note that there is no consensus concerning the comparison between indices calculated from epiphytic and epilithic communities and Hill et al. (2000), Soininen and Eloranta (2004) and Potapova (1996) have collected evidence which cautions against it. Rothfritz et al. (1997) however, compared epilithic and epiphytic diatoms and concluded that sampling from either would give representative results for water quality. Potapova and Charles (2005) argue that studies looking at algal biomass should sample from a single substrate while studies using algal indices, such as the TDI, should not be affected by substrate. In this study, the results are inconclusive and seem to depend on the stretch of the channel sampled and on whether samples were taken from riffles or glides.

\section{LOCATION IN STREAM}

Variation in periphyton biomass between stream stretches and within stream habitats are to be expected and are likely to result from differences in light, disturbance and small scale differences in nutrient gradients around the cells. Glass slides placed in riffle areas were in significantly shallower water than those in the glide areas and therefore received greater light intensities. This feature could allow the periphyton to attain greater biomasses over the month. The quantity of photosynethically-active radiation has been shown to be the most important environmental factor affecting periphyon biomass (Ledger and Hildrew, 1998) though differences in invertebrate grazing pressures between riffles and glides may also have been important. Despite the differences in diatom biomass there were no clear differences in species composition between riffles and glides on the glass slides or on the natural substrates (Figs.3 and 6).

Differences in species composition (Fig. 6) and TDI (Fig.1a) on the natural and artificial substrates between two adjacent stream stretches passing though the same land use, however, was less anticipated. The predominance of Cocconeis placentula on the glass slides in both the riffles and glides in the unfenced stretch and motile Nitzschia species in the riffles in the fenced stretch (Fig. 6) suggests that the former length is particularly affected by high invertebrate grazing pressures (Rosemund et al., 1993; Kelly, 2001) and the latter by more sediment movement. Riffles are characterised by sediment accumulation (Summerfield, 1997; Kelly, 2003) and Round et al. (1990) have noted that motile diatoms Nitszchia are prominent in the diatom flora as a result of increased sedimentation. Such a difference in the predominance of motile diatoms in the riffles between the stretches would have alerted an investigator of TDI to pressures other than water quality governing the result and the TDI for the sites would have been treated with caution as recommended by Kelly (2001). However, the percentage of motile diatoms found on the slides varied between glides and riffles (Fig. 2) and therefore the recording of any change in percentage motility between these two stretches of river may be dependent upon actual in-stream site sampled.

Environmental Change Network sampling guidance requires that sampling takes place where the substrate is not "unduly influenced by localised catchment disturbance" (Sykes et al., 1999). The lower diatom frustule frequency and biomass in the unfenced stretch (Fig. 4a,b) is consistent with disturbance (Biggs et al., 1998). It is not possible to draw conclusions as to the impact on the bank management and the resulting cattle access to the river on the periphytic flora as the authors were unable to study replicated fenced 
and unfenced areas; nevertheless, the study highlights small scale variations which may be overlooked by the diatom sampler.

\section{Conclusions}

This study shows that periphytic diatom species composition, biomass and TDI can vary in response to the substrate sampled, stretch of river chosen, location in stream and - in the case of percent motile frustules - at small, within habitat scales.

The high variability of diatom indices, and species composition within combinations of substrate, fenced/ unfenced and habitat type, suggest that several replicates may be needed to avoid sampling variability confounding the application of diatom indices for water quality monitoring or general ecological assessment.

These variations did not occur consistently between the substrates and in-stream location and it is not clear which stretch of river, or whether riffles or glides, gave the most representative periphytic sample. Indeed, it is the variance in diatom species, biovolume and TDI which is perhaps more interesting than the differences in means as an indicator of the dynamics of change and variability. This feature deserves further investigation, with greater replication between physical stream management practices, habitat types and streams themselves.

The myriad of differing pressures on the periphytic diatom flora at a variety of spatial scales suggests that to gain a representative sample, diatoms should be taken from several natural substrates, where present, and from several locations within the river channel. Soinenen and Kononen (2004) consider that due to this sort of variation, river nutrient monitoring should not rely on diatoms alone but combine several biological elements. It is therefore heartening that the development of monitoring tools for the WFD is concentrating on several biological groups, but there is also a need to ensure that the samples taken are not unduly affected by small scale variations between channel stretches and in-stream morphology.

\section{Acknowledgements}

This study was funded through the NERC CEH projects C01682 Hydrological Functioning of Wetlands and C01753 Modelling In-stream Habitats.

\section{References}

Barbiero, R.P., 2000. A multi-lake comparison of epilithic diatom communities on natural and artifical substrates. Hydrobiologia, 438, $157-170$.
Biggs, B.J.F., Stevenson, R.J. and Lowe, R.L., 1998. A habitat matrix conceptual model for stream periphyton. Archiv. Hydrobiol, 143, 21-56.

Growns, I.O and Growns, J.E., 2001. Ecological effects of flow regulation on macroinvertebrate and periphyton diatom assemblages in the Hawkesbury-nepean River, Australia. Regul. River., 17, 275-293.

Harper, D.M., Kemp, J.L., Vogel, B. and Newson, M.D., 2000. Towards the assessment of 'ecological integrity' in running waters of the United Kingdom. Hydrobiologia, 422, 133-142.

Hill, B.H., Herlihy, A.T., Kaufmann, P.R. Stevenson, R.J., McCormick, F.H. and Johnson, C.B., 2000. Use of periphyton assemblage data as an index of biotic integrity. J. N. Amer. Benthol. Soc., 19, 50-67.

Jongman, R.H.G., ter Braak, C.J.F. and van Tongeren, O.F.R., 1995. Data analysis in community and landscape ecology. Cambridge University Press, Cambridge, UK.

Kelly, M.G., 2003. Short term dynamics of diatoms in an upland stream and implications for monitoring eutrophication. Environ. Pollut., 125, 117-122.

Kelly, M.G. and Whitton, B.A., 1995. The trophic diatom index: a new index for monitoring eutrophication in rivers. J. Appl. Phycol., 7, 433-44.

Kelly, M.G., Cazaubon, A., Coring, E., Dell'Uomo, A., Ector, L., Goldsmith, B., Guasch, H., Hurlimann, J., Jariman, A., Kawecka, B., Kwandrans, J., Laugaste, R., Lindstrom, E.A., Leitao, M., Marvan, P., Padisak., J., Pipp, E., Sabater, S., van Dam, H. and Vizinet, J., 1998. Recommendations for the routine sampling of diatoms for water quality assessments in Europe. J. Appl. Phycol., 10, 215-224.

Kelly, M.G., Adams, C., Graves, A.C., Jamieson, J., Krokowski, J., Lyncett, E.B., Murray-Bligh, J., Pritchard, S. and Wilkins, C., 2001. The Trophic Diatom Index: A user's manual. Revised Edition. Environment Agency Technical Report E2/TR2.

Komarek, O. and Sukacova, K., 2004. The use of artificial substrates in different growth conditions. Ekologia-Bratislava, 23,192-206.

Krammer, K. and Lange-Bertalot, H., 1999. Subwasserflora von Mitteleuropa: Baccillarophyceae. Volumes 1-4. Spektrum Akademischer Verlag GmbH Heidelberg, Berlin, Germany.

Ledger, M. and Hildrew, A.G., 1998. Temporal and spatial variation in the epilithic biofilm of an acid stream. Freshwater Biol. 40, 655-670.

Logan, P. and Furse, M., 2002. Preparing for the European Water Directive - making the links between habitat and aquatic biota. Aquat. Conserv.- Mar. Freshwater Ecosyst., 12, 425-437.

Neal, C., Skeffington, R., Neal, M., Wyatt, R., Wickham, H., Hill, L. and Hewett, N., 2004a. Rainfall and runoff water quality of the Pang and Lambourn, tributaries of the River Thames, southeastern England. Hydrol. Earth Syst. Sci., 8, 601-613.

Neal, C., Jarvie, H.P., Wade, A.J., Neal, M., Wyatt, R., Wickham, H., Hill, L. and Hewitt, N., 2004b. The water quality of the LOCAR Pang and Lambourn catchments. Hydrol. Earth Syst. Sci., 8, 614-635.

Official Journal of the European Communities., 2000. Directive 2000/60/EC of the European Parliament and of the Council of 23 October 2000: Establishing a framework for Community action in the field of water policy.

Pinheiro, J.C. and Bates, D.M., 2000. Mixed-Effects Models in S and S-PLUS. Springer, New York, USA.

Potapova, M., 1996. Epilithic algal communities in rivers of the Kolyma mountains, NE Siberia, Russia. Nova Hedwigia, 63, 309-334

Potapova, M. and Charles, D.F., 2005. Choice of substrate in algaebased water-quality assessment. J. N. Amer. Benthol.Soc., 24, 415-427. 
Redfield, A.C., 1958. The biological control of chemical factors in the environment. Amer. Sci., 46, 205-221.

Rosemund, A.D., Mulholland, P.J. and Ellwood, J.W., 1993. Topdown and bottom-up control of stream periphyton: effects of nutrient and herbivores. Ecology, 74, 1264-1280.

Rothfritz, H., Juttner, I., Suren, A.M. and Ormerod, S.J., 1997. Epiphytic and epilithic diatom communities along environmental gradients in the Nepalese Himalaya: Implications for the assessment of biodiversity and water quality. Arch. Hydrobiol., 138, 465-482.

Round, F.E., Crawford, R.M. and Mann, D.G., 1990. The Diatoms: Biology and Morphology of the Genera. Cambridge University Press, Cambridge, UK.

Smolar, N., Vrhovsek, D and Kosi, G., 1998. Effects of low flow on periphyton in three different types of streams in Slovenia. Adv. River Bottom Ecol., 107-116.

Soininen, J. and Eloranta, P., 2004. Seasonal persistence and stability of diatom communities in rivers: are there habitat specific differences? Eur. J. Phycol., 39, 153-160.
Soininen, J. and Kononen, K., 2004. Comparative study monitoring South-Finnish rivers and streams using macroinvertebrate and benthic diatom community structure. Aquat. Ecol., 38, 63-75.

Summerfield, M.A., 1997. Global Geomorphology. Addison Wesley Longman Ltd, Harlow, Essex, UK.

Sykes, J.M., Lane, A.M.J. and George, G. (Eds), 1999. The U.K. Environmental Change Network: protocols for standard measurements at freshwater sites. Institute of Terrestrial Ecology, Huntingdon, UK.

Whitton, B.A. and Rott, E., 1996. Use of algae for monitoring rivers II. Proceedings of the $2^{\text {nd }}$ European Workshop, Innsbruck, 1995. Universitat Innsbruck. Germany. 196pp.

Zelinka, M. and Marvan, P., 1961. Zur Prazisierung der biologischen Klassifikation des Reinheit fliessender Gewasser. Arch. Hydrobiol., 57, 389-407. 